University of Nebraska - Lincoln

DigitalCommons@University of Nebraska - Lincoln

\title{
Evaluation of light attraction for the stored-product psocid, Liposcelis bostrychophila
}

John Diaz-Montano

USDA-ARS, jd325@cornell.edu

James F. Campbell

USDA-ARS, james.campbell@usda.gov

Thomas W. Phillips

Kansas State University, twp1@ksu.edu

Lee W. Cohnstaedt

USDA-ARS

James E. Throne

USDA-ARS, Manhattan, KS, james.throne@ars.usda.gov

Follow this and additional works at: https://digitalcommons.unl.edu/usdaarsfacpub

Diaz-Montano, John; Campbell, James F.; Phillips, Thomas W.; Cohnstaedt, Lee W.; and Throne, James E., "Evaluation of light attraction for the stored-product psocid, Liposcelis bostrychophila" (2016).

Publications from USDA-ARS / UNL Faculty. 2066.

https://digitalcommons.unl.edu/usdaarsfacpub/2066

This Article is brought to you for free and open access by the U.S. Department of Agriculture: Agricultural Research Service, Lincoln, Nebraska at DigitalCommons@University of Nebraska - Lincoln. It has been accepted for inclusion in Publications from USDA-ARS / UNL Faculty by an authorized administrator of DigitalCommons@University of Nebraska - Lincoln. 


\title{
Evaluation of light attraction for the stored-product psocid, Liposcelis bostrychophila
}

\author{
John Diaz-Montano ${ }^{1} \cdot$ James F. Campbell $^{1} \cdot$ Thomas W. Phillips $^{2}$. \\ Lee W. Cohnstaedt ${ }^{3} \cdot$ James E. Throne $^{4}$
}

Received: 23 September 2015/Revised: 16 December 2015/Accepted: 23 December 2015/Published online: 31 December 2015 (C) Springer-Verlag Berlin Heidelberg (outside the USA) 2015

\begin{abstract}
The psocid, Liposcelis bostrychophila Badonnel (Psocoptera: Liposcelididae), is the most widespread psocid pest of stored products. Because L. bostrychophila has developed resistance to several chemical insecticides, it is important to investigate other integrated pest management (IPM) approaches, and a critical part of IPM programs is an effective monitoring program, Monitoring tools for psocids are limited, and few studies have been conducted on monitoring of psocids, with none on the attraction of lights for psocids. Therefore, we studied the response of $L$. bostrychophila adults to eight wavelengths of light-emitting diodes (LED) in paired-choice pitfall test. Among the LEDs evaluated, the strongest response by $L$. bostrychophila adults was to $351 \mathrm{~nm}$ UV. When LEDs were tested against brewer's yeast (the most preferred attractant for L. bostrychophila among more than 20 potential attractants found in previous studies), the $351 \mathrm{~nm}$
\end{abstract}

Communicated by C. G. Athanassiou.

John Diaz-Montano

jd325@cornell.edu

1 Stored Product Insect and Engineering Research Unit, USDA, Agricultural Research Service, Center for Grain and Animal Health Research, 1515 College Avenue, Manhattan, KS 66502, USA

2 Department of Entomology, Kansas State University, 123 West Waters Hall, Manhattan, KS 66506, USA

3 Arthropod-Borne Animal Diseases Research Unit, USDA, Agricultural Research Service, Center for Grain and Animal Health Research, 1515 College Avenue, Manhattan, KS 66502, USA

4 USDA, Agricultural Research Service, San Joaquin Valley Agricultural Sciences Center, 9611 South Riverbend Avenue, Parlier, CA 93648, USA
UV wavelength was the only light that attracted more psocids than brewer's yeast. These results suggest that the use of LEDs might be useful in psocid-monitoring programs for L. bostrychophila and other psocid species.

Keywords Liposcelis bostrychophila Psocoptera: Liposcelididae · Stored products · Grains · Monitoring · Light preferences - Behavior

\section{Key message}

- Psocids are stored-product pests of increasing concern worldwide, and monitoring tools are limited. For the first time, the use of Light-Emitting Diodes (LED) for attraction of the main psocid species, Liposcelis bostrychophila, was explored.

- Eight LEDs in combination with brewer's yeast (attractant highly preferred by L. bostrychophila) and/ or blank controls were tested in choice tests.

- The LED emitting $351 \mathrm{~nm}$ UV light elicited the strongest response by $L$. bostrychophila adults. This response was even stronger than for brewer's yeast.

\section{Introduction}

Psocids are stored-product pests of increasing economic importance, and Liposcelis bostrychophila Badonnel (Psocoptera: Liposcelididae) is one of the most commonly found species (Mills et al. 1992; Turner 1994). This psocid has been reported in Australia (Rees and Walker 1990; Rees 1994), Asia (Leong and Ho 1994; Rajendran 1994; Rees 1994; Wang et al. 1999, 2000b), Africa (Lienhard and 
Smithers 2002), South America, (Lienhard and Smithers 2002), Europe (Turner 1994, 1998), Canada (Mills et al. 1992), and the U.S. (Throne 2010; Phillips and Throne 2010). Psocids can cause significant damage and reductions in grain weight of stored products such as rice, Oryza sativa L. (McFarlane 1982; Rees and Walker 1990) and wheat, Triticum aestivum L. (Gautam et al. 2013; Kučerová 2002), and contamination of food commodities (Turner 1994; Athanassiou et al. 2010b). Additionally, several psocids have been documented to be resistant to the fumigant phosphine (Ho and Winks 1995; Nayak et al. 1998; 2003; Nayak and Collins 2008; Nayak et al. 2014), contact insecticides such as carbamates (Nayak et al. 1998), pyrethroids (Nayak et al. 1998, 2002; Opit et al. 2012), organophosphates (Ding et al. 2002; Dou et al. 2006), pyrethrins (Athanassiou et al. 2009), spinosad (Nayak et al. 2005; Athanassiou et al. 2009), and the insect growth regulator methoprene (Athanassiou et al. 2010a).

Psocids associated with stored products move in and out of the food material and have been shown to respond to environmental conditions such as temperature and moisture or relative humidity. Opit et al. (2009) observed that populations of psocids in steel bins were more abundant at the center of the bin during the fall where temperature and grain moisture content were higher that in other parts of the bin. In laboratory tests, L. bostrychophila responded to temperature gradients (Throne and Flinn 2013) and moisture gradients (Diaz-Montano et al. 2014a), with a preference for the warmest and highest moisture regions. However, how stored-product psocids respond to light conditions has not been investigated. Environments where stored-product insects are found have highly variable light conditions, from dark inside bulk grain to light on grain surface, outside bins, and packaged food materials. $L i$ poscelis bostrychophila has seven ommatidia, two oval and five round, with normal smooth surfaces (Yang et al. 2015) and thus the potential to respond to light; however, it is not certain if this response is reduced in stored-product species since they are often found in dark habitats.

Monitoring tools are essential components of integrated pest management (IPM) programs, but few studies have been conducted to address how to most effectively monitor stored-product psocids. Brewer's yeast-baited traps have been used to monitor psocids in domestic household surveys in the U.K. (Turner and Maude-Roxby 1989; Turner and Bishop 1998). Opit et al. (2009) observed that commercially available pitfall-type traps and corrugated cardboard refuges were effective methods to sample psocids [Liposcelis entomophila (Enderlein) and L. decolor (Pearman)]. However, different attractants or combinations of attractants might increase psocid captures in traps. $\mathrm{Li}$ poscelis bostrychophila preferred substrates with fungal extracts over control substrates (Green 2008), and preferred yellow millet over other grains, with addition of brewer's yeast to yellow millet increasing response (Green and Turner 2005). Diaz-Montano et al. (2014b, 2015) performed a systematic evaluation of different available potential volatile chemical attractants for seven psocid species, including $L$. bostrychophila, and found that they strongly responded to volatile odors coming from brewer's yeast, wheat germ, and/or wheat germ oil.

The attraction of many insects to light has been documented, but we are not aware of any studies addressing this topic with psocids. There have been some studies on the attraction of other stored-product pests to different wavelengths of light. Kirkpatrick et al. (1970) tested attraction to green and ultraviolet (UV) light by several stored-product pest insects using suction light traps under simulated warehouse conditions, and they observed that a significant number of cigarette beetles, Lasioderma serricorne (Fabricius), flat grain beetles, Cryptolestes pusillus (Schönherr), and lesser grain borers, Rhyzopertha dominica (Fabricius) preferred the UV light, whereas higher numbers of almond moth, Cadra cautella (Walker), and the Indian meal moth, Plodia interpunctella (Hübner), selected the green light. Highest numbers of red flour beetles, Tribolium castaneum (Herbst), and rice weevils, Sitophilus oryzae (L.), were observed on traps with a combination of green and UV lights. In similar studies in laboratory rooms and peanut warehouses, Soderstrom (1970) observed greater numbers of Indian meal moth and Mediterranean flour moth, Ephestia kuehniella Zeller, responding to green lights, while the cigarette beetle, merchant grain beetle, Oryzaephilus mercator (Fauvel), rice weevil, red flour beetle, and lesser grain borer responded to UV lights. Sheribha et al. (2010) evaluated the light preference of red flour beetle using a multicolor device system and found that adults preferred clear, blue, and green lights and avoided red light. Duehl et al. (2011) tested light attraction of red flour beetle in a cloverleaf shape arena with four Light-Emitting Diodes (LEDs), and they found that significantly more adults were attracted to $390 \mathrm{~nm}$ UV compared to 360 and $380 \mathrm{~nm}$ UV and $410 \mathrm{~nm}$ blue light. Park et al. (2015) studied the response of the maize weevil, Sitophilus zeamais (Motshulsky), to five LEDs using a Y-maze chamber and observed that these beetles were more attracted to red $(625 \mathrm{~nm})$ followed by yellow $(590 \mathrm{~nm})$ and infrared $(730 \mathrm{~nm})$. In similar experiments, Jeon et al. (2012) found that the rice weevil were more attracted to blue $(450 \mathrm{~nm})$ followed by green $(520 \mathrm{~nm})$, red $(660 \mathrm{~nm}), \mathrm{UV}(365 \mathrm{~nm})$, and infrared $(730 \mathrm{~nm})$. Sambaraju and Phillips (2008) studied the response of the Indian meal moth when given a choice between dark areas or areas with UV $(395 \mathrm{~nm})$, green $(525 \mathrm{~nm})$, or white $(450-700 \mathrm{~nm})$ lights; insects preferred the illuminated areas and UV elicited the strongest response. Cowan and Gries (2009) 
studied the attraction of Indian meal moths to lights in a wind tunnel with two and four-choice experiments and found that UV (350 nm) and blue (405 nm) attracted more males and mated and virgin females. The identification of specific light wavelengths that attract psocids could be an important factor to enhance the monitoring of psocids. Therefore, the objective of this study was to evaluate attraction of the most important psocid pest L. bostrychophila to different specific wavelengths of light.

\section{Materials and methods}

\section{Insect culture}

The L. bostrychophila population (voucher specimen No. 202, Kansas State University Museum of Entomological and Prairie Arthropod Research) used in this study was from cultures that were started in 2006 with psocids collected from a grain elevator in Manhattan, KS. Psocids were reared on a diet of $95 \%$ cracked hard red winter wheat (Titricum aestivum L. 'Santa Fe'), $2 \%$ wheat germ (Natural Raw Wheat Germ, Bob's Red Mill Natural Foods Inc., Milwaukie, OR), $2 \%$ brewer's yeast (MP Biomedicals, Solon, $\mathrm{OH}$ ), and $1 \%$ crisped rice cereal (Rice Krispies, Kellogg's Company, Battle Creek, MI) at $30{ }^{\circ} \mathrm{C}$, $65 \% \mathrm{RH}$, and a photoperiod of 16:8 L:D h. Mixed-age adults [between 0 and 90 days; adult longevity is 89.4 days at $30{ }^{\circ} \mathrm{C}$ (Wang et al. 2000a)] from a 3-6 month old culture of $L$. bostrychophila were evaluated in the experiments.

\section{Experimental bioassay}

The response of L. bostrychophila to LED colors was evaluated in paired-choice tests in a Petri dish with openings on opposite sides through which lights and/or chemical cues contained in vials entered the arena, and psocids that responded were captured in the vials (Fig. 1). The arena consisted of a polystyrene Petri dish $(14 \mathrm{~cm}$ in diameter by $1.4 \mathrm{~cm}$ in height). The walls of this Petri dish had two holes opposite each other $(5.0 \mathrm{~mm}$ in diameter and $14 \mathrm{~cm}$ apart along the diameter mid-line of the dish) and level with the bottom of the Petri dish. An acrylic tube $(5.0 \mathrm{~mm}$ in outer-diameter, $3.0 \mathrm{~mm}$ in inner-diameter, $1.7 \mathrm{~cm}$ in length) was inserted in each hole of the Petri dish. The other end of the acrylic tube was connected to an acrylic vial $(2.5 \mathrm{~cm}$ diameter by $5.4 \mathrm{~cm}$ height $)$ through a hole $(5.0 \mathrm{~mm}$ in diameter) located on the upper part of the vial $(1.0 \mathrm{~cm}$ from the top). The acrylic vial had a second hole directly opposite (5.0 $\mathrm{mm}$ diameter), where the LED light was inserted. The acrylic vials were covered with black tape to block light escaping. The interior walls of the Petri dish and the acrylic vials were coated with

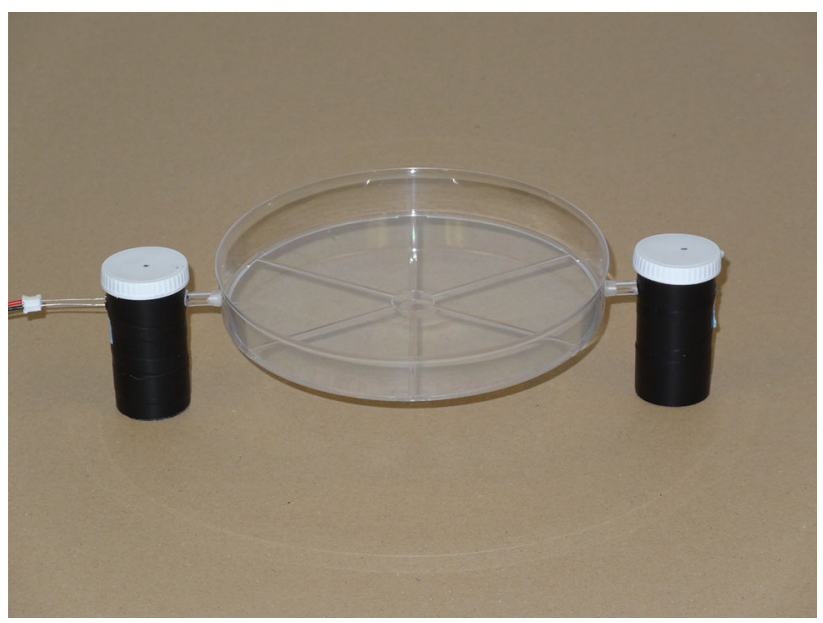

Fig. 1 Paired-choice pitfall arena

polytetrafluoroethylene (60 wt \% dispersion in water, Sigma-Aldrich Co., St. Louis, MO) to prevent psocid climbing and capture psocids in the vials. The LEDs were powered by a rechargeable sealed lead acid battery (SP620, 6V 20AH/NB, SigmasTek, New York, NY) through a potentiometer (RV4NAYSD152A, 2 W Power Rating, 1.5 $\mathrm{kOhm}$ Resistance Value, Honeywell International Inc., Morristown, NJ).

There were six experiments in which paired-choice tests were conducted using acrylic vials that contained different treatments (Table 1). These treatments included LEDs (eight different wavelengths) alone or in combination with brewer's yeast, paired with a blank vial as control, or a vial with brewer's yeast only. Brewer's yeast (1 g) was included for evaluation because it elicited the strongest response for several psocid species in previous experiments (DiazMontano et al. 2014b, 2015). Eight LEDs with different wavelengths were evaluated: four ultraviolet (UV) lights: 351 nm (L5-1-U5TH15-1, LEDSupply, Randolph, VT), 380 nm (RL5-UV0230-380, Super Bright LEDs Inc. St. Louis, MO), 390 nm (LED-5U8PK20, Lightobject, Sacramento, CA), and 400 nm (RL5-UV0430-400, Super Bright LEDs Inc. St. Louis, MO); violet: $420 \mathrm{~nm}$ (RL5-V1015, Super Bright LEDs Inc. St. Louis, MO), blue: $470 \mathrm{~nm}$ (RL5-B2430, Super Bright LEDs Inc. St. Louis, MO),

Table 1 List of paired-choice experiments in this study

\begin{tabular}{lll}
\hline Experiment & Vial 1 & Vial 2 \\
\hline I & Light & Blank \\
II & Light & Brewer's yeast \\
III & Light + Brewer's yeast & Blank \\
IV & Light + Brewer's yeast & Brewer's yeast \\
V & Light + Brewer's yeast & Light \\
VI & Brewer's yeast & Blank \\
\hline
\end{tabular}


green: 527 nm (RL5-G7032, Super Bright LEDs Inc. St. Louis, MO), and red: $660 \mathrm{~nm}$ (RL5-R1330, Super Bright LEDs Inc. St. Louis, MO). Another experiment was conducted to confirm the earlier findings by Diaz-Montano et al. (2014b) that L. bostrychophila responds strongly to brewer's yeast. This earlier study used a different bioassay, so it was important to confirm that this species responds to brewer's yeast when presented as described here. A choice test was conducted comparing choice between a vial with brewer's yeast and a blank control vial.

Because the white light is a mixture of the colors of the visible spectrum, additional experiments were performed to observe the response of $L$. bostrychophila to clear white LED (IL151, Microtivity, Hong Kong). Paired tests were conducted to compare the choice between a vial with a clear white LED and a blank control vial, as well as the choice between a vial with a clear white LED and a vial with brewer's yeast.

Fifteen psocid adults were collected and placed in a small polystyrene Petri dish $(3.5 \mathrm{~cm}$ in diameter). Food was withheld from the psocids for $24 \mathrm{~h}$ prior to adding to the arenas. The Petri dish was turned over carefully at the center of the arena, and the lights from the room were turned off. After a 10-min acclimation period, the small Petri dish was removed, and psocids were allowed to move freely in the large dish arena. After $4 \mathrm{~h}$, the number of psocids outside (in the arena) and inside each acrylic vial was counted. The experiments were conducted in a walk-in growth chamber under dark conditions at $25{ }^{\circ} \mathrm{C}$ and $65 \%$ RH.

\section{Experimental design and analysis}

The experiments were performed in the order presented in Table 1. The treatments within each experiment were performed randomly until 10 replications per each LED light were completed, in a randomized complete block design. Analysis of variance (ANOVA) was conducted to compare the numbers of $L$. bostrychophila adults captured in the vials in the treatments (vial 1 or vial 2). Post hoc multiple comparisons were conducted using Tukey's studentized range test (SAS Institute 2008). Pairwise comparisons were analyzed separately to compare the number of psocids captured between the two vials.

\section{Results}

\section{Experiment I: Light versus blank}

Across the different light treatments, more L. bostrychophila adults responded to the $351 \mathrm{~nm}$ UV light vial compared to vials with blue, violet, and red light
$(F=10.7 ; \mathrm{df}=7,9 ; P<0.001)$ (Table 2). The pairwise comparisons showed that significantly more psocids preferred the LED lights compared to the blank control, except for the red light treatment $(F=4.1 ; \mathrm{df}=1,9$; $P=0.0738)$ (Table 2).

\section{Experiment II: Light versus Brewer's yeast}

The strongest response by psocid adults across the vials with different light wavelengths was to $351 \mathrm{~nm}$ UV $(F=21.3 ; \mathrm{df}=7,9 ; P<0.001)$, with double the capture compared to the other light wavelengths (Table 3). Psocids significantly preferred brewer's yeast $(F=8.1 ; \mathrm{df}=7,9$; $P<0.001$ ) over all the LED wavelengths, except for the $351 \mathrm{~nm}$ UV treatment (Table 3). The pairwise comparisons showed that significantly more psocids preferred the vials with brewer's yeast compared to the different wavelength lights evaluated, except for $351 \mathrm{~nm} \mathrm{UV}$, where there was preference for the vial with light over brewer's yeast $(F=23.0 ; \mathrm{df}=1,9 ; P<0.001)$ (Table 3).

\section{Experiment II: Light + Brewer's yeast versus blank}

There were no significant differences in the number of psocids captured among the different vials with light + brewer's yeast treatments $(F=0.9 ; \quad \mathrm{df}=7, \quad 9$; $P=0.5105)$, nor among captures in the blank control among treatments $(F=0.93 ; \mathrm{df}=7,9 ; \quad P=0.4863)$ (Table 4). For all treatments, the pairwise comparison showed that significantly more psocids responded to the light + brewer's yeast compared to the blank control (Table 4).

Table 2 Number (mean $\pm \mathrm{SE}$ ) out of 15 individuals of L. bostrychophila mixed-age adults that in a paired-choice test selected the treatment vial when given a choice between a specific wavelength LED light and a blank control

\begin{tabular}{lcc}
\hline LED Light & Vial 1 (Light) & Vial 2 (Blank) \\
\hline UV-351 nm & $10.1 \pm 0.3 \mathrm{aA}$ & $2.9 \pm 0.4 \mathrm{aB}$ \\
UV-390 nm & $8.7 \pm 0.6 \mathrm{abA}$ & $3.2 \pm 0.3 \mathrm{aB}$ \\
UV-400 nm & $8.7 \pm 0.4 \mathrm{abA}$ & $3.3 \pm 0.4 \mathrm{aB}$ \\
Green-527 nm & $8.3 \pm 0.5 \mathrm{abA}$ & $3.1 \pm 0.4 \mathrm{aB}$ \\
UV-380 nm & $8.1 \pm 0.3 \mathrm{abcA}$ & $2.9 \pm 0.5 \mathrm{aB}$ \\
Blue-470 nm & $7.5 \pm 0.6 \mathrm{bcdA}$ & $3.4 \pm 0.6 \mathrm{aB}$ \\
Violet-420 nm & $6.1 \pm 0.5 \mathrm{cdA}$ & $4.2 \pm 0.4 \mathrm{aB}$ \\
Red-660 nm & $5.5 \pm 0.3 \mathrm{dA}$ & $4.5 \pm 0.4 \mathrm{aA}$ \\
\hline
\end{tabular}

Average of 10 replicates

Means followed by different lowercase letters within a column or different capital letters within a row are significantly different $(P<0.05$, Tukey's test $)$ 
Table 3 Number (mean \pm SE) out of 15 individuals of L. bostrychophila mixed-age adults that in a paired-choice test selected the treatment vial when given a choice between a specific wavelength LED light and brewer's yeast

\begin{tabular}{lll}
\hline LED Light & Vial 1 (Light) & Vial 2 (Brewer's Yeast) \\
\hline UV-351 nm & $8.1 \pm 0.3 \mathrm{aA}$ & $5.2 \pm 0.4 \mathrm{bB}$ \\
UV-380 nm & $4.2 \pm 0.4 \mathrm{bB}$ & $8.3 \pm 0.7 \mathrm{aA}$ \\
$\mathrm{UV}-390 \mathrm{~nm}$ & $3.6 \pm 0.8 \mathrm{bcB}$ & $8.6 \pm 0.7 \mathrm{aA}$ \\
$\mathrm{UV}-400 \mathrm{~nm}$ & $3.0 \pm 0.3 \mathrm{bcdB}$ & $8.7 \pm 0.8 \mathrm{aA}$ \\
Violet-420 nm & $2.4 \pm 0.5 \mathrm{bcdB}$ & $9.6 \pm 0.7 \mathrm{aA}$ \\
Green-527 nm & $2.2 \pm 0.8 \mathrm{bcdB}$ & $10.5 \pm 0.8 \mathrm{aA}$ \\
Blue-470 nm & $1.8 \pm 0.4 \mathrm{cdB}$ & $10.3 \pm 0.6 \mathrm{aA}$ \\
Red-660 nm & $1.3 \pm 0.4 \mathrm{~dB}$ & $11.2 \pm 0.8 \mathrm{aA}$ \\
\hline
\end{tabular}

Average of 10 replicates

Means followed by different lowercase letters within a column or different capital letters within a row are significantly different $(P<0.05$, Tukey's test $)$

Table 4 Number (mean \pm SE) out of 15 individuals of L. bostrychophila mixed-age adults that in a paired-choice test selected the treatment vial when given a choice between a specific wavelength LED light + brewer's yeast and a blank control

\begin{tabular}{lcc}
\hline LED Light & Vial 1 (Light + Brewer's Yeast) & Vial 2 (Blank) \\
\hline UV-380 nm & $10.7 \pm 0.7 \mathrm{aA}$ & $1.9 \pm 0.4 \mathrm{aB}$ \\
UV-351 nm & $10.3 \pm 0.4 \mathrm{aA}$ & $3.2 \pm 0.5 \mathrm{aB}$ \\
Red-660 nm & $9.8 \pm 0.3 \mathrm{aA}$ & $3.0 \pm 0.3 \mathrm{aB}$ \\
UV-390 nm & $9.7 \pm 0.8 \mathrm{aA}$ & $2.9 \pm 0.7 \mathrm{aB}$ \\
Violet-420 nm & $9.6 \pm 0.3 \mathrm{aA}$ & $2.9 \pm 0.4 \mathrm{aB}$ \\
Green-527 nm & $9.5 \pm 0.3 \mathrm{aA}$ & $3.1 \pm 0.4 \mathrm{aB}$ \\
UV-400 nm & $9.5 \pm 0.5 \mathrm{aA}$ & $3.4 \pm 0.6 \mathrm{aB}$ \\
Blue-470 nm & $9.3 \pm 0.4 \mathrm{aA}$ & $3.4 \pm 0.6 \mathrm{aB}$ \\
\hline
\end{tabular}

Average of 10 replicates

Means followed by different lowercase letters within a column or different capital letters within a row are significantly different $(P<0.05$, Tukey's test $)$

\section{Experiment IV: Light + Brewer's yeast versus Brewer's yeast}

In the treatment light + brewer's yeast vials across the different treatments, significantly $(F=4.4$; df $=7,9$; $P<0.001)$ more psocid adults responded to the $351 \mathrm{~nm}$ UV light vial compared to vials with red, 380 and $390 \mathrm{~nm}$ UV, and blue light combined with brewer's yeast (Table 5). Psocid response to the other vial (brewer's yeast alone) was not significantly different $(F=0.9$; df $=7,9$; $P=0.5366$ ) among the treatments (Table 5). The pairwise comparisons showed that only for the $351 \mathrm{~nm} \mathrm{UV+}$ brewer's yeast treatment were significantly $(F=27.9$; df $=1,9 ; P<0.001)$ more psocids found in the light and brewer's yeast vials compared to the brewer's yeast treatment (Table 5).

\section{Experiment V: Light + Brewer's yeast versus light}

There were no significant differences in the number of psocids responding to vials with light and brewer's yeast across the different treatments (except for response to $351 \mathrm{~nm}$ UV being significantly less than response to red light) $(F=2.9$; df $=7,9 ; P<0.001)$ (Table 6). There were no significant $(F=1.3$; df $=7,9 ; P=0.2552)$ differences in response to the light only vial across the different treatments (Table 6). The pairwise comparisons showed that significantly more psocids responded to the light + brewer's yeast treatment compared to the light alone treatment, regardless of the light wavelength (Table 6).

\section{Experiment VI: Brewer's yeast versus blank}

In this experiment to confirm an earlier study, significantly $(F=227.8 ; \mathrm{df}=1,9 ; P<0.001)$ more L. bostrychophila adults were found in the vial with brewer's yeast (11.2 \pm 0.3$)$ compared to the blank control (2.2 \pm 0.4$)$. The percentage of adults that responded to brewer's yeast was $75 \%$, and this was similar to the percentage observed in Diaz-Montano et al. (2014b).

\section{Experiment VII: Response of L. bostrychophila to clear white LED}

Significantly $(F=29.27$; df $=1,9 ; P<0.001)$ more $L$. bostrychophila adults were found in the blank control vial (4.6 \pm 0.9$)$ compared to the vial containing the clear white LED (0.9 \pm 0.4$)$. More psocids also were found in the vial with brewer's yeast $(10.5 \pm 0.3)$ compared to the vial with the white light $(1.7 \pm 0.3) \quad(F=396.0 ; \quad$ df $=1, \quad 9$; $P<0.001)$.

\section{Discussion}

Liposcelis bostrychophila adults responded strongly to lights in the UV spectrum, with the strongest response to $351 \mathrm{~nm}$ UV LED. When given a choice between responding to light or food odor (brewer's yeast), this psocid species preferred the food, except when presented with the $351 \mathrm{~nm}$ UV wavelength light which attracted more psocids than brewer's yeast alone. In a previous study, Diaz-Montano et al. (2014b) evaluated the response of $L$. bostrychophila to more than 20 potential attractants, and it was observed that brewer's yeast elicited the most consistent strong response from this psocid species. These results indicate that $351 \mathrm{~nm}$ UV light triggers a very strong phototaxis response from $L$. bostrychophila adults even when competing with brewer's yeast volatiles, and may be 
Table 5 Number (mean \pm SE) out of 15 individuals of $L$. bostrychophila mixed-age adults that in a paired-choice test selected the treatment vial when given a choice between a specific wavelength LED light + brewer's yeast and brewer's yeast

\begin{tabular}{lll}
\hline LED Light & Vial 1 (Light + Brewer's Yeast) & Vial 2 (Brewer's Yeast) \\
\hline UV-351 nm & $8.8 \pm 0.4 \mathrm{aA}$ & $5.1 \pm 0.3 \mathrm{aB}$ \\
UV-400 nm & $7.3 \pm 0.5 \mathrm{abA}$ & $5.7 \pm 0.5 \mathrm{aA}$ \\
Violet-420 nm & $7.3 \pm 0.7 \mathrm{abA}$ & $6.2 \pm 0.6 \mathrm{aA}$ \\
Green-527 nm & $6.2 \pm 0.7 \mathrm{abA}$ & $6.2 \pm 0.7 \mathrm{aA}$ \\
Red-660 nm & $5.8 \pm 0.5 \mathrm{bA}$ & $6.5 \pm 0.5 \mathrm{aA}$ \\
UV-390 nm & $5.7 \pm 0.8 \mathrm{bA}$ & $6.5 \pm 0.5 \mathrm{aA}$ \\
UV-380 nm & $5.5 \pm 0.7 \mathrm{bA}$ & $6.7 \pm 0.9 \mathrm{aA}$ \\
Blue-470 nm & $4.7 \pm 0.8 \mathrm{bA}$ & $6.4 \pm 0.7 \mathrm{aA}$ \\
\hline
\end{tabular}

Average of 10 replicates

Means followed by different lowercase letters within a column or different capital letters within a row are significantly different $(P<0.05$, Tukey's test $)$
Table 6 Number (mean $\pm \mathrm{SE}$ ) out of 15 individuals of L. bostrychophila mixed-age adults that in a paired-choice test selected the treatment vial when given a choice between a specific wavelength LED light + brewer's yeast and a specific wavelength LED light

\begin{tabular}{lll}
\hline LED Light & Vial 1 (Light + Brewer's Yeast) & Vial 2 (Light) \\
\hline Red-660 nm & $9.9 \pm 0.3 \mathrm{aA}$ & $2.2 \pm 0.3 \mathrm{aB}$ \\
UV-390 nm & $8.7 \pm 0.5 \mathrm{abA}$ & $2.8 \pm 0.3 \mathrm{aB}$ \\
UV-400 nm & $8.6 \pm 0.6 \mathrm{abA}$ & $3.4 \pm 0.8 \mathrm{aB}$ \\
Blue-470 nm & $8.2 \pm 0.8 \mathrm{abA}$ & $1.7 \pm 0.3 \mathrm{aB}$ \\
UV-380 nm & $8.2 \pm 0.9 \mathrm{abA}$ & $2.4 \pm 0.5 \mathrm{aB}$ \\
Violet-420 nm & $8.2 \pm 0.9 \mathrm{abA}$ & $2.0 \pm 0.5 \mathrm{aB}$ \\
Green-527 nm & $7.1 \pm 0.9 \mathrm{abA}$ & $2.6 \pm 0.7 \mathrm{aB}$ \\
UV-351 nm & $5.7 \pm 0.7 \mathrm{bA}$ & $1.8 \pm 0.6 \mathrm{aB}$
\end{tabular}

Average of 10 replicates

Means followed by different lowercase letters within a column or different capital letters within a row are significantly different $(P<0.05$, Tukey's test $)$

a potential attractant for monitoring where background food odors are present such as in a food facility. It is also possible that $L$. bostrychophila response to food baited traps may be reduced if used outside in the presence of sunlight, although we did not find a response to the full spectrum white light so this may be less of an issue. Further tests of food attractants alone should consider the interaction of response with light.

The combination of light and brewer's yeast appears to be a good synergistic attractant. When the eight light wavelengths were combined with brewer's yeast and tested against brewer's yeast, only the $351 \mathrm{~nm}$ UV + brewer's yeast attracted more psocids compared to the other combinations, and for all other treatments, similar numbers were captured in both vials regardless of the presence of LED lights. When lights + brewer's yeast were tested against lights alone, psocids were more attracted to the treatment with lights and brewer's yeast than to the treatments with lights only. In the $351 \mathrm{~nm}$ UV treatment, the lowest recorded number of psocids made a choice, as most of the insects stayed on the arena and did not enter either vial. This observation again shows the strong preference of $L$. bostrychophila adults for $351 \mathrm{~nm}$ UV over brewer's yeast, because psocids preferred to stay on top of the arena than make a choice.

When psocids were given the choice of the LED lights versus the blank controls, they selected the treatment vial with lights, with the exception of treatment with red light and blank control, where the number of psocids found on both sides was similar. The highest percentages of $L$. bostrychophila adults that responded to the lights were observed on 351, 390, and $400 \mathrm{~nm} \mathrm{UV}$, green and $380 \mathrm{~nm}$ UV $(67,58,58,55$, and $54 \%$, respectively). In the experiment where brewer's yeast was compared against the blank control, the percentage of $L$. bostrychophila adults that responded to brewer's yeast was $75 \%$. These results confirm the strong response by $L$. bostrychophila to the brewer's yeast and some of the LEDs tested, in particular the $351 \mathrm{~nm}$ UV light.

Most insects possess UV, blue and green photoreceptors that have maximum sensitivity at $\sim 350 \mathrm{~nm}, \sim 440 \mathrm{~nm}$, and $\sim 530 \mathrm{~nm}$, respectively (Briscoe and Chittka 2001). This is generally the case for stored-product pest beetles, such as L. serricorne, C. pusillus, O. mercator, T. castaneum, $R$. dominica, and $S$. oryzae, and pest moths such as C. cautella, E. kuehniella, and P. interpunctella (Kirkpatrick et al. 1970; Soderstrom 1970; Sambaraju and Phillips 2008; Cowan and Gries 2009; Sheribha et al. 2010; Duehl et al. 2011). Sitophilus zeamais may be an exception, since it also responded to red $(625 \mathrm{~nm})$, yellow $(590 \mathrm{~nm})$, and infrared $(730 \mathrm{~nm})$ light (Park et al. 2015), although the preference of yellow and infrared light was not significantly different from the preference for blue $(470 \mathrm{~nm})$ and green $(520 \mathrm{~nm})$ light. Liposcelis bostrychophila appears to be sensitive to a wide range of wavelengths, since when given a choice of light versus blank, there was a significant 
and positive response to all wavelengths except for $660 \mathrm{~nm}$ red light (neutral response) and clear white LED (negative response). However, the strongest response of $L$. bostrychophila was to light in the UV range, with strongest response to the shortest wavelength tested $(351 \mathrm{~nm})$.

In this study, we determined the strong response by $L$. bostrychophila to LEDs producing $351 \mathrm{~nm}$ wavelengths. The strong response suggests that this might be a useful attractant for monitoring devices, especially given the strong response even in the presence of a food attractant. Future research should evaluate the attraction to this wavelength of light by other psocid species in order to determine if the same LED (351 nm UV) can attract multiple psocid species. Ultimately the use of traps with UV light LEDs alone or in combination with food attractants such as brewer's yeast needs to be evaluated to determine effectiveness under more realistic conditions found inside and outside food facilities where environmental conditions such as temperature and moisture content and dark/illuminated areas may influence psocid movement patterns.

\section{Author contribution}

JC, JD, JT, LC, and TP conceived the study. JD designed the study, performed the experiments, analyzed the data, and wrote the manuscript. JC, JT, LC, and TP revised and improved the manuscript.

Acknowledgments We thank Ann Redmon, Brian Barnett, and Richard Hammel for excellent technical assistance. TWP was supported by the Kansas Agricultural Experiment Station. Mention of trade names or commercial products in this publication is solely for the purpose of providing specific information and does not imply recommendation or endorsement by the U.S. Department of Agriculture or Kansas State University. USDA is an equal opportunity provider and employer.

\section{References}

Athanassiou CG, Arthur FH, Throne JE (2009) Efficacy of grain protectants against four psocid species on maize, rice and wheat. Pest Manag Sci 65:1140-1146

Athanassiou CG, Arthur FH, Throne JE (2010a) Efficacy of methoprene for control of five species of psocids (Psocoptera) on wheat, rice, and maize. J Food Prot 73:2244-2249

Athanassiou CG, Opit GP, Throne JE (2010b) Influence of commodity type, percentage of cracked kernels, and wheat class on population growth of stored-product psocids (Psocoptera: Liposcelidae). J Econ Entomol 103:985-990

Briscoe AD, Chittka L (2001) The evolution of color vision in insects. Annu Rev Entomol 46:471-510

Cowan T, Gries G (2009) Ultraviolet and violet light: attractive orientation cues for the Indian meal moth, Plodia interpunctella. Entomol Exp Appl 131:148-158
Diaz-Montano J, Campbell JF, Flinn PW, Throne JE (2014a) Distribution of three psocid species (Psocoptera: Liposcelididae) in different moisture gradients in wheat. J Stored Prod Res 59:172-177

Diaz-Montano J, Campbell JF, Phillips TW, Throne JE (2014b) Evaluation of potential attractants for Liposcelis bostrychophila (Psocoptera: Liposcelididae). J Econ Entomol 107:867-874

Diaz-Montano J, Campbell JF, Phillips TW, Throne JE (2015) Evaluation of potential attractants for six species of storedproduct psocids (Psocoptera: Liposcelididae, Trogiidae). J Econ Entomol 108:1398-1407

Ding W, Wang JJ, Zhao ZM, Tsai JH (2002) Effects of controlled atmosphere and DDVP on population growth and resistance development by the psocid, Liposcelis bostrychophila Badonnel (Psocoptera: Liposcelididae). J Stored Prod Res 38:229-237

Dou W, Wang JJ, Zhao ZM (2006) Toxicological and biochemical characterizations of GSTs in Liposcelis bostrychophila Badonnel (Psocop., Liposcelididae). J Appl Entomol 130:251-256

Duehl AJ, Cohnstaedt LW, Arbogast RT, Teal PEA (2011) Evaluating light attraction to increase trap efficiency for Tribolium castaneum (Coleoptera: Tenebrionidae). J Econ Entomol 104:1430-1435

Gautam SG, Opit GP, Giles KL, Adam B (2013) Weight loss and germination failure caused by psocids in different wheat varieties. J Econ Entomol 106:491-498

Green PWC (2008) Fungal isolates involved in biodeterioration of book-paper and their effects on substrate selection by Liposcelis bostrychophila (Badonnel) (Psocoptera: Liposcelididae). J Stored Prod Res 44:258-263

Green PWC, Turner BD (2005) Food-selection by the booklouse, Liposcelis bostrychophila Badonnel (Psocoptera: Liposcelididae). J Stored Prod Res 41:103-113

Ho SH, Winks RG (1995) The response of Liposcelis bostrychophila Badonnel and L. entomophila (Enderlein) (Psocoptera) to phosphine. J Stored Prod Res 31:191-197

Jeon JH, Oh MS, Cho KS, Lee HS (2012) Phototactic response of the rice weevil, Sitophilus oryzae linnaeus (Coleoptera: Curculionidae), to light-emitting diodes. J Korean Soc Appl Biol Chem 55:35-39

Kirkpatrick RL, Yancey DL, Marzke FO (1970) Effectiveness of green and ultraviolet light in attracting stored-product insects to traps. J Econ Entomol 63:1853-1855

Kučerová Z (2002) Weight losses of wheat grains caused by psocid infestation (Liposcelis bostrychophila: Liposcelididae: Psocoptera). Plant Prot Sci 38:103-107

Leong ECW, Ho SH (1994) Relative tolerance of Liposcelis bostrychophila (Bad.) and L. entomophila (End.) to some organophosphorus and carbamate insecticides. Int J Trop Insect Sci 15:343-349

Lienhard C, Smithers CN (2002) Psocoptera (insecta) world catalogue and bibliography. Instrumenta Biodiversitatis V, Museum of Natural History, Geneva

McFarlane JA (1982) Damage to milled rice by psocids. Trop Stored Prod Inf 44:3-10

Mills JT, Sinha RN, Demianyk CJ (1992) Feeding and multiplication of a psocid Liposcelis bostrychophila Badonnel (Psocoptera: Liposcelidae) on wheat, grain screenings, and fungi. J Econ Entomol 85:1453-1462

Nayak MK, Collins PJ (2008) Influence of concentration, temperature and humidity on the toxicity of phosphine to the strongly phosphine resistant psocid Liposcelis bostrychophila Badonnel (Psocoptera: Liposcelididae). Pest Manag Sci 64:971-976

Nayak MK, Collins PJ, Reid SR (1998) Efficacy of grain protectants and phosphine against Liposcelis bostrychophila, L. entomophila, and L. paeta (Psocoptera: Liposcelididae). J Econ Entomol 91:1208-1212 
Nayak MK, Collins PJ, Kopittke RA (2002) Comparative residual toxicities of carbaryl, deltamethrin and permethrin as structural treatments against three liposcelidid psocid species (Psocoptera: Liposcelididae) infesting stored commodities. J Stored Prod Res 38:247-258

Nayak MK, Collins PJ, Pavic H, Kopittke RA (2003) Inhibition of egg development by phosphine in the cosmopolitan pest of stored products Liposcelis bostrychophila (Psocoptera: Liposcelididae). Pest Manag Sci 59:1191-1196

Nayak MK, Daglish GJ, Byrne VS (2005) Effectiveness of spinosad as a grain protectant against resistant beetle and psocid pests of stored grain in Australia. J Stored Prod Res 41:455-467

Nayak MK, Collins PJ, Throne JE, Wang JJ (2014) Biology and management of psocids infesting stored products. Annu Rev Entomol 59:279-297

Opit GP, Throne JE, Flinn PW (2009) Evaluation of five sampling methods for the psocids Liposcelis entomophila and L. decolor (Psocoptera: Liposcelididae) in steel bins containing wheat. J Econ Entomol 102:1377-1382

Opit GP, Arthur FH, Throne JE, Payton ME (2012) Susceptibility of stored-product psocids to aerosol insecticides. J Insect Sci 12:1-14

Park JH, Sung BK, Lee HS (2015) Phototactic behavior 7: phototactic response of the maize weevil, Sitotroga zeamais motsch (Coleoptera: Curculionidae), to light-emitting diodes. J Korean Soc Appl Biol Chem 58:373-376

Phillips TW, Throne JE (2010) Biorational approaches to managing stored-product insects. Annu Rev Entomol 55:375-397

Rajendran S (1994) Psocids in food commodities and their control. Pestology 28:14-19

Rees D (1994) Distribution and status of psocoptera infesting stored products in Australia. In: Highley E, Wright EJ, Banks HJ, Champ BR (eds) Proceedings of the 6th international working conference on stored-product protection, 17-23 April 1994, Canberra, Australia. CAB International, Wallingford, pp 583-587

Rees DP, Walker AJ (1990) The effect of temperature and relative humidity on population growth of three Liposcelis species (Psocoptera: Liposcelidae) infesting stored products in tropical countries. Bull Entomol Res 80:353-358

Sambaraju KR, Phillips TW (2008) Responses of adult Plodia interpunctella (Hübner) (Lepidoptera: Pyralidae) to light and combinations of attractants and light. J Insect Behav 21:422-439

SAS Institute (2008) SAS 9.2 for Windows. SAS Institute Inc, Cary
Sheribha PRB, Jinham AP, Das SSM, Jasmine KR (2010) Management of Tribolium castaneum (Herbst) based on hue response. Turk J Zool 34:367-375

Soderstrom EL (1970) Effectiveness of green electroluminescent lamps for attracting stored-product insects. J Econ Entomol 63:726-731

Throne JE (2010) Overview of North American stored product research. In: Carvalho MO, Fields PG, Adler CS, Arthur FH, Athanassiou CG, Campbell JF, Fleurat-Lessard F, Flinn PW, Hodges RJ, Isikber AA, Navarro S, Noyes RT, Riudavets J, Sinha KK, Thorpe GR, Timlick BH, Trematerra P, White NDG (eds) Proceedings of the 10th international working conference on stored product protection, 27 June to 2 July 2010, Estoril, Portugal. Julius Kühn-Institut, Berlin, pp 42-49

Throne JE, Flinn PW (2013) Distribution of psocids (Psocoptera) in temperature gradients in stored wheat. J Stored Prod Res $55: 27-31$

Turner BD (1994) Liposcelis bostrychophila (Psocoptera: Liposcelidae), a stored food pest in the UK. Int J Pest Manag 40:179-190

Turner BD (1998) Psocids as a nuisance problem in the UK. Pestic Outlook 9:27-30

Turner BD, Bishop J (1998) An analysis of the incidence of psocids in domestic kitchens: the PPFA 1997 household survey (What's bugging your kitchen). Environ Health J 106:310-314

Turner BD, Maude-Roxby H (1989) The prevalence of the booklouse Liposcelis bostrychophilus Badonnel (Liposcelidae, Psocoptera) in British domestic kitchens. Int Pest Control 31:93-97

Wang JJ, Zhao ZM, Li LS (1999) Induced tolerance of the psocid, Liposcelis bostrychophila Badonnel (Psocoptera: Liposcelididae), to controlled atmosphere. Int J Pest Manag 45:75-79

Wang JJ, Tsai JH, Zhao ZM, Li LS (2000a) Development and reproduction of the psocid Liposcelis bostrychophila (Psocoptera: Liposcelididae) as a function of temperature. Ann Entomol Soc Am 93:261-270

Wang JJ, Zhao ZM, Tsai JH (2000b) Resistance and some enzyme activities in Liposcelis bostrychophila Badonnel (Psocoptera: Liposcelididae) in relation to carbon dioxide enriched atmospheres. J Stored Prod Res 36:297-308

Yang Q, Kučerová Z, Perlman SJ, Opit GP, Mockford EL, Behar A, Robinson WE, Stejskal V, Li Z, Shao R (2015) Morphological and molecular characterization of a sexually reproducing colony of the booklouse Liposcelis bostrychophila (Psocodea: Liposcelididae) found in Arizona. Sci Rep 5:10429 